\title{
A Study of Mother Tongue Interference in Pronunciation of College English Learning in China
}

\author{
Jianping Luo \\ Guangdong University of Petrochemical Technology, China
}

\begin{abstract}
There exists a phenomenon of pronunciation confusion of [n] with [1], which appears among the College English learners who come from the provinces along the Yangzi River regions in China and speak their hometown dialects. And something alike happens to the other dialect speakers from the south of China, who could hardly distinguish [f] from [h], or to the Zhuang dialect speakers who could hardly distinguish the aspirated sounds from the non-aspirated ones. These college students usually unintentionally transfer these confused pronunciation of their hometown dialects to English pronunciation and make pronunciation confusion when they speak and read aloud English, which is called mother tongue interference. What's more, this phenomenon also occurs among some teachers who are from these dialect regions. This paper has discussed and analyzed the causes of these mispronunciations phonologically, and then points out some solutions to help both College English teachers and students to realize and overcome their problems. Also, this paper suggests that: first, some knowledge of phonology is necessary to tell phones apart from phonemes; second, as a College English teacher, he or she should learn something about the phonetic features of the students' dialects so as to predict what mistakes these learners would probably make when speaking and reading English; third, helping learners with their pronunciation correction practice is an essential part of the teacher's job, and use of learning strategies, group activities and self-directed learning or autonomous learning ideas and so on is much helpful to guide the classroom teaching and learning.
\end{abstract}

Index Terms-phone, phoneme, phonology, mother tongue interference, Chinese dialects, English pronunciation, college English teaching and learning

\section{INTRODUCTION}

\section{A. College English Learners in Chinese Universities and Colleges}

English is one required course called College English in China for almost all students of universities and colleges according to the College English Curriculum Requirements issued by the Chinese Minister of Education (2007). In any one of the universities or colleges today, there are almost students who come from inside or outside of the province in which the university or college is located. A local college in Guangdong Province, for example, has a lot of students who come from more than twenty provinces like Hunan, Hubei, Jiangsu, Jiangxi, Shanxi, Shandong, Guangxi, Anhui, Sichuan, Gansu, Fujian, Yunnan, Hainan, and even Nei Mongol the province north far away from the province where that college is situated (Huang Ling-yan \& Luo Jun, 2011). These students speak different dialects of their hometown, which would likely more or less cause some trouble for English pronunciation.

\section{B. The Problems of These Students' English Pronunciation}

Some students who come from Hunan Province would find it hard to distinguish the English pronunciation between the alveolar nasal sound [n] and the alveolar liquid lateral sound [1]. For example, they would incline to pronounce "knife" for "life", "need" for "lead", or something like that. But on the contrary, some students from Hubei Province would likely pronounce "life" for "knife", "lead" for "need", and so on. In teaching practice, such things usually happen to those students who come from the regions along the Yangzi River, like the provinces of Sichuan, Chongqing, Jiangsu, etc. Besides, some students of Zhuang nationality from Guangxi would likely pronounce "gat" for "cat", and "bark" for "park", and so on. What is wrong with these dialect speakers? Why do they habitually make such wrong pronunciation? Generally speaking, these phenomena are called mother tongue interference, which frequently happens in second language teaching and learning, and today still remains a hot topic for scholars (Akinwamide, T. Kolade, 2012; Elina Tergujeff, 2012) to discuss and study.

As William Littlewood (2002) points out in his book named Foreign and Second Language Learning that the interference results from the fact that the learner uses what he already knows about language, in order to make sense of new experience. In the case of mother tongue interference, the learner uses his previous mother-tongue experience as a means of organizing the second language phones. In fact, surprisingly, surveys from university and college in China obviously show that not only students but also teachers are often found to be much confused with such interference problems in the course of College English teaching and learning (Luo Jian-ping \& Huang Ling-yan, 2008). 


\section{Purposes of This Paper}

So, the purpose of this paper is intended to look into the phenomenon, discuss the problem of mother tongue interference in English pronunciation, analyze the causes from phonology and then suggest some solutions to solve these problems mentioned above for College English teaching and learning.

\section{CAuse Analysis}

\section{A. Some Chinese Dialects and Their Pronunciation}

Chinese language consists of eight dialects, with Putonghua as the standard based on Beijing and Northeastern regions. The eight dialects are spoken mainly in eight regions, but in each region there are also a lot of sub-dialects which are different from each other a little. Chinese university students would like to speak their hometown dialects in daily life, especially when they meet those school friends who come from the same province and get together. Sometimes, their utterance sounds quite ridiculous or funny to those from the other dialect regions. For example, if the students from Lanzhou or Chongqing want to say "the sky is blue, and the earth is green" in Putonghua, they would habitually pronounce it as "Tian shi $N A N$ de, di shi $N U$ de", instead of "Tian shi $L A N$ de, di shi $N U$ de", which might cause a burst of laughter immediately because their utterence sounds like "the sky is male, and the earth is female" to those who come from the other provinces like Guangdong, Henan, etc. So, it is clear that these mispronunciations are closely related to their hometown dialects. And actually their English pronunciation is also somehow interfered by their dialect pronunciations, which happened more frequently in local colleges according to some surveys (Huang Ling-yan, 2011).

\section{B. English Teaching in the Middle Schools in These Regions}

Usually, those students who are likely to pronounce English sounds in the same way as they do their hometown dialect sounds do not have any chance to go out of their hometown before they go to universities or colleges. They attended middle schools in their hometown, where their middle school teachers would probably speak the same hometown dialect and did not notice that funny phenomenon, or they also have much obstacle to do the correction, to say nothing of helping their students with the right pronunciation. In fact, this is an often-seen phenomenon in the countryside schools in these dialect regions, especially in those backward mountainous rural schools. To College English teachers, it is a hard job to help these students to pronounce English sounds correctly because they have been long misled when they were young in their middle school.

\section{Phonology Difference between English and Chinese}

Academically, as the scholar points out, English is an intonation language and intonation is meaningful, while Chinese is a tone language which uses tone to distinguish meanings (Zhang Qingxong, 2011). So, there must be a lot of differences in the number of phones and the ways of sound combination between the two languages. Generally speaking, for example, in English phonetic system there are twenty vowels and twenty-four consonants, but in Chinese phonetic system there are only six vowels (or monophthongs), twenty-five consonants and four tones (Wei Zhi-cheng, 2003) which do not exist in English. And therefore wrong transfer would be sparked again and again in the course of the foreign language learning. In fact, the phenomenon called "mother tongue interference" mentioned above is often found in foreign language teaching at the level of pronunciation, morphology, syntax, vocabulary acquisition, lexicology (Luo Jian-ping, 2013), etc. The Chinese students learning English would come across more or less pronunciation interference at the very beginning, no matter where they are from, as different languages have different sound systems, or phonological systems. And therefore, pronunciation problems would unavoidably come up here and there in English learning.

In most cases, the cause of pronunciation interference is much related with phonology. In phonology, the sounds [n] and [1] are two different phonemes in both English and Chinese Putonghua, but in some dialects in the region of Yangzi River, they are only a group of sounds representing one phoneme. So, when these dialect speakers go out of their dialect regions and communicate with people in other dialect regions, the substitution of [n] for [1] would sound funny or even cause trouble in understanding. Something like that also happens in the other dialect regions. For example, in some local dialect regions in Jiangxi Province, local people always pronounce [f] for [h], and some people in the east of Guangdong Province would pronounce $[\mathrm{g}]$ for $[\mathrm{j}]$.

\section{Solution to THE Problem}

\section{A. Some Knowledge of Phonology Is Necessary}

It seems that some knowledge of phonology will help us a lot with the matter. For example, it will certainly help to predict what problems some dialect speaking students might have and find ways to solve the interference caused by their mother tongues in learning College English.

Phonology is the study of the sound patterns in different human languages, and speech sounds are in themselves physically different from each other in a number of ways, such as place of articulation, manner of articulation, voicing, tongue height, etc (Hu Zhuanglin, 2001). They may also function differently in different languages. So, for the question 
mentioned above, some knowledge of phones, phonemes, allophones is first necessary.

A PHONE is a phonetic or segment. The speech sounds we hear and produce during linguistic communication are all phones. For instance, in the words: pit, spit, tip, we have the phones: [p’] (as in pit), [p] (as in spit), [p?] (as in tip). But the three different phones do not reflect any difference in meaning. That is to say, if [p'] is pronounced in "spit" incorrectly, the sound would not cause any confusion in meaning, and the speaker is just only considered to be poor in English pronunciation. So, we say that these three phones are just regarded as the same phone as [p] which is called phoneme.

A PHONEME is a phonological unit with distinctive value, which is one key point that should be kept in mind. In English, the example again, the aspirated [p'] as in "pit" and the non-aspirated [p] as in "spit" are just phones, rather than a phoneme as discussed above, but in Chinese, the two phones are quite different from each other in meaning. Take two Chinese characters pronounced as $p$ 'in and pin for example, the former with the aspirated [p'] means "fight" or "try hard", and the latter with the non-aspirated [p] means "guest" or "soldier" (but only spelt as "bin" in the Chinese Phonetic System). So, in Chinese Putonghua pronunciation, [p'] and [p] are regarded as two different phonemes, not just two phones, because they represent two different meanings.

Strictly speaking, every sound is different from each other, and even the intended repetition of a sound will be different every time when it is produced. But, in phonology some of the differences are ignored, and the phonologist is only concerned with what differences are significant or distinctive (Dai, Weidong \& He Zhaoxiong, 2002). A good way of reasoning is comparison (Luo Jian-ping, 2011), just like the comparison of the aspirated [p'] with non-aspirated sounds [p]. In English, they are non-distinctive, but in Chinese Putonghua, they are significant in meaning. In order to determine which sounds are distinctive, the customary practice is to set up MINIMAL PAIRS, a pair of words which differ from each other only by one sound. The scholar explains it in the linguistic course book that, for example, in the English words tip, there are three separate speech sounds or phonemes, that is /t, I, p/. In a further English word lip, there are speech sounds, /l, I, p/. The only difference between tip and lip is the initial sound in each word and the meaning of the words. When we substitute /t/ for / $/$ in this way and bring about a change in meaning, we say that the sounds in question are phonemes and that there is a phonemic distinction between them (Yang Xinzhang, 2005).

So actually a phoneme is not any particular sound, but an abstract unit just as a word is an abstract unit (Dwight Bolinger, 1999). A phoneme is represented or realized by a certain phone in a certain phonetic context. Take the example of sound [p] again, an aspirated [p'] is always at the beginning of the phonetic context like pit, the non-aspirated [p] usually appears after the sound [s] as in spit, and the stop [p $\urcorner$ ] is only seen at the end as in tip. The three sounds constitute a group of sounds represented only by the phoneme [p]. Then, such a group of sounds are phonologically called ALLOPHONES.

Allophones are the non-distinctive forms of a phoneme, which are used in two ways. One way is in COMPLEMENTARY DISTRIBUTION, which can be seen as above. The other way is in FREE VARIATION. In some situations, for instance, some English speakers pronounce [e] or [i] for the beginning sound of the word "economics" differently, and do not change the meaning of the word at all. That is to say, the two phones occur in the same position without an apparent change of meaning, and so here in that case, [e] and [i] are allophones in free variation.

Back to the confusion of [n] and [1]in some Chinese diatects, the dialect speakers in Hunan Province would always pronounce [n] for [1], but the speakers in Hubei Province would utter [1] in place of [n]. To their dialects, [n] and [1] are allophones in free variation.

\section{B. Some Knowledge of Dialects Is a Basic Job}

Not only the phonology knowledge but some knowledge of difference of language and dialect is also certainly necessary for College English teaching and learning, which might help to predict what kind of trouble would occur in pronunciation training, and help to realize and analyze the mispronunciation caused by mother tongue interference, and finally help learners to do their correction.

In universities and colleges today in China, students come from every part of China, north or south, east or west, not only just the local students themselves as before. All kinds of regional dialects would come along with these regional dialect speakers into a new university environment, and the so-called mother tongue interference would certainly occur and might put some of them into an embarrassing situation when reading and speaking, or even sometimes form a conflict among these new freshmen.

Following is the difference of English and Chinese pronunciations, first. In Chinese Putonghua phonetics system, there are almost no such minimal pairs as voiceless and voiced sounds as in English, but there exist the pairs as aspirated and non-aspirated sounds. So, for the students from the north like Henan, Shanxi province, they would find it difficult in distinguishing the voiceless from voiced sounds like [s] and [z]. They are inclined to add a vowel after these sounds and might pronounce [sə] for [s], [fə] for [f]. For example, they might read worker for work, and better for bet, and so on. Besides, in Chinese there do not exist some dental friction sounds like [ $\theta$ ], and thus quite a lot of Chinese students are likely to utter [sin] for "thin", and something like that (Zhang Qingzong, 2011).

Second, another difference which causes pronunciation trouble also exists between various dialects. In Cantonese, the dialect spoken in most part of Guangdong Province, Hong Kong, and some part of Guangxi Province, the phonetics system has voiceless and voiced sounds ( $\mathrm{Li}$ Zhuomin, 1980) and so the students of this regional dialect would not mispronounce the sounds like $[\mathrm{s}],[\mathrm{z}],[\mathrm{t}],[\mathrm{d}],[\mathrm{k}],[\mathrm{g}]$, etc. but the other regional dialect speakers would probably do. 
Like the Hunan dialect speakers, the students from Nanjing, Chongqing, Lanzhou and Hubei would also are likely to confuse [n] with [1]. Besides, the students from Jiangxi Province are likely to confuse the sounds [f] and [h], which is also likely to happen to the students of Cantonese speakers in most part of Guangdong Province and some part of Guangxi Province. Take "lake" for example, in Putonghua system they would utter [fu] (sounded like "beard") instead of [hu] (lake). And so in English speaking and reading, the mispronunciation of "fardly" for "hardly" is often heard from these dialect speakers.

For the students from Zhuang natives of Guangxi Province, they are found difficult to distinguish the aspirated sounds from the non-aspirated ones. And when they speak Putonghua, their customary non-aspirated utterances might often cause laughing from other dialect speakers. For example, when they pronounce the Chinese expression like "da feng kou" ( meaning "big wind gap"), they would often mispronounce it as "da feng gou", which sounds like "a big mad dog" in Putonghua, and so at once causes a burst of laughter. What's more, for the Chinese expression like "have a look", they would incorrectly pronounce the word "look" as gangan (do), rather than kankan (see or look) in Putonghua. There is joke about the Zhuang dialect pronunciation that a native, who found a beautiful girl over there and wanted to go over and have a look, says "let's go over and "gangan" the girl", which first surprised his friends of Putonghua speakers and then caused laughter from them, because the Putonghua pronunciation of gangan means rape, not look, which should be pronounced as kankan.

\section{Pronunciation Correction Practice Is an Essential Job}

Practice makes perfect. The students should be directed to do pronunciation correction practice. They should be divided into mixed groups, which are good for learning practice (Huang Ling-yan, 2010). The so-called mixed groups mean that, in every group, there are students from all dialect regions, or from all provinces, or from the north and the south, but never at all from just one dialect region in one group, because in the mixed group they could easily find what is wrong and how to make correction of English pronunciation. For example, it would be difficult for a student from Hunan to find the pronunciation confusion of [n] and [1], let alone to say help right practice, but it will be easy for a student from Guangdong to find it wrong and help make correction training. Again, a student from Zhuang dialect region in Guangxi would also probably ignore the mispronunciation of aspirated sounds made by those who speak the same region dialect as he or she, but a student from other dialect regions might probably easily detect the mispronunciation immediately at the time when it occurs.

Learning College English needs strategies (Huang Ling-yan, 2010), so it is with the practice of pronunciation training. A good language teacher is good at directing learners to use learning strategies like self-help learning, self-directed learning or autonomous learning (Tricia Hedge, 2002). A tongue twister is a good help for pronunciation training. Though the tongue twister is a language game and may seem funny, yet it is a good practice for those Chinese English speakers who have a problem of mispronunciation. You may begin with the easy ones like "a bitter biting bittern", "a lusty lady", "a flea and a fly", "a big black bug", "do tongue twisters twist your tongue?", and so on. It is said that the toughest tongue twister in the English language is "sixth sick sheik's sixth sheep's sick". Teachers could arrange those students practice tongue twisters before the blackboard, in groups, and even after class or at home. Both English and Chinese tongue twisters are a good practice for correcting the mispronunciation. In all, learners should often read out loud their English vocabulary words not only tongue twisters.

Finally, remember that these pronunciation training and practice should be organized on the notion of learner-centered learning. Some scholars (Freeman \& Richards, 2002) believe that learner-centered learning is good for positive classroom relationships and ensures that the learners' affective needs are considered. They hold that it is important to increase the learners' confidence and to establish a positive and nonthreatening classroom environment. Apart from the group activities, it is necessary for the teacher to conduct an action research to solve his or her such problems found in classroom learning (Luo Jian-ping, 2013), and mother tongue does exert interference in second language learning,. Only when the teacher does researches, could he or she really makes such matter clear and help the dialect speakers understand the cause of their problems. That would be helpful for them to act positively and enjoy doing their practice of pronunciation correction training consciously and energetically.

\section{CONCLUSION}

To sum up, many a Chinese college student would come across more or less the problem of mother tongue interference. Many of them would unintentionally confuse the phoneme [n] with [1], or [f] with [h], or the aspirated sounds with the non-aspirated ones in the course of learning English pronunciation, including some teachers who speak their hometown dialects instead of the standard Chinese. Both students and teachers might hardly avoid the mother tongue interference in learning or teaching a foreign language. Interference does not only occur at the level of pronunciation because of the different phonological systems between English and Chinese, but also appears at the other levels like collocation (Abdul Ali Mphil, 2013) and writing (Somchai W. Siriluck Usaha, 2013). So, as a teacher of English as a foreign language, he or she should have in mind some knowledge of linguistic theory and the ability to do research on problems found in classroom teaching. Facing the problem of mother tongue interference, we do not mean to "get it right from the beginning on form" (Lightbown, Patsy M, \& Spada, Nina, 2002) for foreign language learners, especially for the beginners, but the most important thing is that a right imitation and practice may be a proper way to success 
from the very beginning,. The College English learners who are likely to make mispronunciation should be helped to realize the causes and do more practice purposefully, just as the old saying "Practice makes perfect". For the College English language teachers, they should be first equipped with some linguistic theories to research and analyze the causes theoretically they have found in teaching practice (Huang Ling-yan, 2001), because only the linguistic knowledge and phonological discussion could save them from the puzzles they have encountered in classroom activities, and make themselves enabled to guide their students to analyze and settle such problems as mentioned above.

\section{REFERENCES}

[1] Bolinger, Dwight. (1999). Aspects of Language. Beijing. Foreign Language Teaching and Research Press. (52).

[2] Dai, Weidong \& He Zhaoxiong. (2002). A New Concise Course on Linguistics for Students of English. Shanghai. Shanghai Foreign Language Education Press. (23-25).

[3] Freeman, Donald \& Richards, Jack C.. (2002). Teacher Learning in Language Teaching. Shanghai. Shanghai Foreign Language Education Press. (164).

[4] Hedge, Tricia. (2002). Teaching and Learning in the Language Classroom. Shanghai, Shanghai Foreign Language Education Press. (76-77)

[5] Hu Zhuanglin. (2001). Linguistic. A Course Book (second edition). Beijing, Beijing University Press. (18).

[6] Huang Ling-yan.(2001). Analysis of Entrance Scores and Improvement of English Teaching. Journal of Ainzhou Teachers College. 3: 74-76.

[7] Huang, Ling-yan \& Luo, Jian-ping. (2011). Correlation Analysis of Reading Comprehension in CET4 Based on Corpus. Journal of Shaoguan University. (7):81-83.

[8] Huang, Ling-yan, \& Luo, Jun. (2011). On CET4-6 and the Strategic Significance of College English Course. Journal of Educational Institute of Jilin Province. 8: 51-52.

[9] Huang, Ling-yan. (2001). Distinction of Simile Between English and Chinese. Journal of Qinzhou Teachers College. 3: 41-45.

[10] Huang, Ling-yan. (2010). Distinction of Simile Between English and Chinese. Journal of Maoming University. 5: 41-45.

[11] Huang, Ling-yan. (2013). Strategies of Memorizing College English Words From Lists and Cards. Journal of Jiamusi Education Institute. 8, 339+344.

[12] Kolade, Akinwamide Timothy. (2012). Imperatives of Information and Communication Technology (ICT) for Second Language Learners and Teachers. English Language Teaching. 1: 44-48.

[13] Li, Zhuomin. (1980). Lishi Chinese Dictionary. Hong Kong. Chinese Language University Press of Hong Kong. (21).

[14] Lightbown, Patsy M, \& Spada, Nina. (2002). How Languages Are Learned. Shanghai. Shanghai Foreign Language Education Press. (119).

[15] Littlewood, Willian. (2002). Foreign and Second Language Learning. Beijing. Foreign Language Teaching and Research Press and the Press of the University of Cambridge, Cambridge. (25).

[16] Luo, Jian-ping \& Huang Ling-yan. (2008). "Shift in Voice" or "Shift in Point of View"? --- An Analysis of English Coherence. Journal of Putian University. 6: 41-45.

[17] Luo, Jian-ping. (2011). Application of Grammatically metaphor to the Analysis of Simile and Metaphor. Journal of Fujian Institute of Education. 3, 105-107.

[18] Luo, Jian-ping. (2013) An Action Research on Improvement of Reading Comprehension of CET4. English Language Teaching. 4: 89-96.

[19] Mphil, Abdul Ali. (2013). Investigating Collocation Errors of Pakistani EFL Learners. The International Journal of Language Learning and Applied Linguistics World. 4: 28-30.

[20] Somchai Watcharapunyawong, Siriluck Usaha. (2013), Thai EFL Students' Writing Errors in Different Text Types: The Interference of the First Language. English Language Teaching. 1: 67-78.

[21] Tergujeff, Elina. (2012). English Pronunciation Teaching: Four Case Studies from Finland. Journal of Language Teaching and Research. 4: 599-607.

[22] The Chinese Minister of Education. (2007). College English Curriculum Requirements. Shanghai: Shanghai Foreign Language Education Press. (23).

[23] Wei, Zhi-cheng. (2003). An Introduction to Comparative Studies of English and Chinese. Shanghai. Shanghai Foreign Language Education Press. (19).

[24] Yang, Xinzhag. (2005). An Introduction to Linguistics. Beijing. Higher Education Press.

[25] Zhang, Qingzong. (2011). Psychological Principles of Foreign Language Learning and Teaching. Beijing. Foreign Language Teaching and Research Press. (200-201).

Jianping Luo was born in Guangzhou, China. He received his bachelor degree in linguistics from Guangzhou Institute of Foreign Languages, China in 1980s.

He is currently an associate professor in the School of Foreign Languages, Guangdong University of Petrochemical Technology, Maoming, Guangdong, China, and was the dean of the Foreign Language Department of Maoming University from 2002 to 2007. His research interests include linguistics and College English learning. 